\title{
Koselleck/koselleck: notas sobre experiência e biografia*
}

\author{
Koselleck/koselleck: Notes on Experience and Biography
}

NIKLAS, Olsen. History in the Plural: an Introduction to the Work of Reinhart Koselleck. New York: Berghahn Books, 2012. 346 p.

\section{Eugenia Gay}

eugeniagay@hotmail.com

Doutora

Pontifícia Universidade Católica do Rio de Janeiro

Rua Marquês de São Vicente, 225 - Gávea

22451-900 - Rio de Janeiro - RJ

Brasil

\section{Palavras-chave}

Biografia; Historiografia alemã; Reinhart Koselleck.

Keywords

Biography; German historiography; Reinhart Koselleck. 
O livro de Niklas Olsen aparece como a primeira e, sem dúvida, ansiosamente aguardada biografia intelectual do historiador alemão Reinhart Koselleck, falecido há já mais de sete anos, em 2006. A rigor, o livro de Olsen se propõe como uma introdução ao trabalho de Koselleck mais do que como uma biografia em sentido estrito, o que justificaria até certo ponto algumas lacunas do texto. No entanto, o autor trabalha a partir da perspectiva de que a vida do biografado é indissociável do seu desenvolvimento teórico de maturidade, a Historik, visto como um produto da soma das suas experiências. Justamente com o objetivo de mostrar essa trajetória experiencial, o biógrafo começa o seu desenho com um capítulo sobre as características sociais da família de Koselleck e sobre a influência que tais determinações tiveram na educação do historiador e nos seus rumos intelectuais. Devido a essa estratégia de construção do argumento, o leitor fica sempre entre a reconstrução biográfica e a análise interpretativa, o que constitui uma perspectiva sumamente válida e geralmente muito frutífera, mas que, neste caso, cria uma expectativa que não sempre se cumpre no trabalho em si.

O estudo de Olsen pretende mostrar que não somente a formação acadêmica de Koselleck, mas também as próprias experiências vividas durante a guerra e como parte do universo acadêmico, resultaram na constituição de um habitus e de uma identidade peculiares que outorgam sentido ao seu trabalho, que se caracteriza por uma ampla multiplicidade de assuntos e perspectivas. Para compreender o caminho da construção da obra de Koselleck, isto é, da 302 formação desse habitus, Olsen estabelece o lugar do historiador dentro do universo intelectual da academia alemã do período posterior à Segunda Guerra Mundial. Nesse contexto, Koselleck é identificado com a geração dos forty-fivers, que Dirk Moses havia caracterizado também como "a geração cética" devido a sua descrença generalizada em relação a qualquer teoria de progresso, e que possibilitou uma espécie de "mediação" entre a geração dos mandarins decadentes do pós-guerra e os "revolucionários" de 68. E nessa parte de fato mais propriamente biográfica do trabalho, mas que constitui o sustento da tese principal do livro, a grande ausência é de uma discussão que dê conta da verdadeira batalha pela identidade que tem se desenvolvido na profissão histórica alemã durante as últimas décadas e que questiona justamente as construções da identidade nacional histórica a partir da atribuição de responsabilidades a respeito do Holocausto.

Particularmente, a Wehrmacht, da qual Koselleck fez parte (também fez parte da Hitlerjugend), viu-se no meio de uma dura polêmica depois da Wehrmachtsausstellung realizada pelo Hamburger Institut für Sozialforschung, em 1999, sendo alvo inclusive de um atentado a bomba durante sua turnê, o que dá a dimensão da gravidade da discussão. Essa exposição, junto com outros debates mais ou menos contemporâneos, desatou uma verdadeira enxurrada de trabalhos e investigações sobre a participação da população em geral e, em particular, dos historiadores mais destacados do pós-guerra no massacre dos judeus ou no projeto nacional-socialista. A exposição mostrava, acima de tudo, a participação direta da Wehrmacht nas matanças de judeus, que havia sido 
negada nas versões iniciais do relato oficial sobre o Holocausto. O problema em disputa era o da legitimidade da história contada, pois se, tradicionalmente, o historiador sustenta a sua credibilidade intelectual na perseguição da verdade e na defesa de alguma classe de objetividade histórica, o ocultamento ou a tergiversação da própria responsabilidade no fato mais controvertido da historia nacional vinha a pôr em questão não só a autoridade moral do sujeito, mas principalmente toda a produção acadêmica do dito historiador. Nesse sentido, as perguntas que Olsen não se dispõe a responder e, de fato, nem sequer se fazem são a de qual foi a atitude de Koselleck em vista dessa discussão sobre a ocultação mais ou menos intencional de uma participação mais ou menos ativa dos historiadores no projeto nacional-socialista ou nas matanças de judeus e a de como se insere a "história de guerra" que Koselleck contou sobre ele mesmo nessa discussão. Se, como nos é lembrado em várias oportunidades, a história e as experiências de vida de Koselleck, e principalmente aquelas que o levaram perto da morte, são o que outorga sentido ao seu trabalho, então uma explicitação sobre a posição do biografado na disputa mencionada, ou, para o caso, pelo menos um posicionamento do biógrafo, pareceria fundamental. Porém, não é esse o caso. Olsen passa por cima da discussão da historiografia alemã sobre a participação das suas maiores figuras no Holocausto na mesma medida em que utiliza (como se faz especificamente na página 75) o fundamento experiencial para explicar a aproximação mais "existencial" de Koselleck ao trabalho de outros intelectuais. Em definitivo, por momentos Olsen parece justificar a validade das posições de Koselleck por via da autoridade da testemunha, enquanto que se recusa a avaliar a validade de um testemunho fartamente questionável.

Em 1947, depois de ter passado pelo cativeiro russo e depois do fim da guerra, Koselleck conseguiu ingressar na Universidade de Heidelberg pela mobilização de alguns contatos da família. Em Heidelberg se reuniam algumas das maiores figuras da intelectualidade alemã e se discutiam os novos rumos do conhecimento histórico em meio à reconstrução e também aos julgamentos da ocupação aliada. Nessa universidade, Koselleck entrou em contato com seus principais mestres e referentes, entre os que se contam Carl Schmitt (com quem manteve contato até a sua morte), Johannes Kühn, Martin Heidegger, Hans-Georg Gadamer, Werner Conze e Otto Brunner. Já como professor, Koselleck participou do Arbeitskreis für moderne Sozialgeschichte, que veio a reformular o que no nacional-socialismo havia sido batizado como Volksgeschichte e do qual nasceu o projeto do Dicionário de Geschichtliche Grundbegriffe. Novamente, teria sido de interesse para os estudiosos da historiografia de Koselleck que o autor aproveitasse o seu acesso de primeira mão (o projeto da biografia nasceu justamente de um encontro com Koselleck) para indagar com mais profundidade sobre as relações entre Koselleck e o Arbeitskreis. Sem uma descrição mais material, por assim dizer, do que se passava no Círculo, o nascimento do Dicionário parece envolvido em uma névoa que se assemelha a um nascimento mítico mais do que a uma discussão intelectual. Continuamos sem ter uma avaliação crítica das relações entre Koselleck e o grupo Conze-Brunner, o grupo da história dos conceitos de Gadamer e o projeto da história dos conceitos 
desenvolvido pelo biografado. Os intelectuais com que Koselleck se formou aparecem como "influências" na sua formação e, em alguns casos (como o de Schmitt em particular), os seus trabalhos são analisados em si mesmos, mas, em geral, falta uma avaliação conscienciosa da relação entre essas teorias e o trabalho de Koselleck.

E o mesmo problema é constatado no caso da relação de Koselleck com a escola de Bielefeld de História Social. A única referência a essa mudança é a que adverte que, com a sua transferência para a Universidade de Bielefeld em 1974, as experiências de Koselleck com os filósofos e historiadores de Heidelberg seriam determinantes para o desenvolvimento de uma perspectiva histórica original, inovadora e eclética. Diz-se muito pouco sobre a sua relação com os outros historiadores de Bielefeld, como Jürgen Kocka ou Hans Ulrich Wehler, ou com o projeto da História Social (Gesellschaftsgeschichte) alemã em geral. Nesse contexto, Olsen caracteriza o trabalho de Koselleck como uma série de tentativas de desbancar a ideia de uma "história em singular" e de refutar tanto o relativismo histórico quanto o "utopismo" mediante o desenvolvimento de uma teoria de "historias em plural" que, na maioria das vezes, não podem ser moldadas segundo as expectativas do historiador. Se essa intepretação descreve a atitude de Koselleck, considerando o esforço enciclopédico do Dicionário, por um lado, e, por outro, a Historik entanto filosofia da história, é uma discussão à parte.

De qualquer maneira, Olsen afirma realizar a interpretação da obra de Koselleck a partir dos processos de recepção e transformação de discursos de outros intelectuais, que assumiram na sua obra características específicas por conta de uma diversidade de fatores. Analisando essa recepção em algumas de suas obras, Olsen refaz o caminho traçado por Koselleck desde a posição de outsider da profissão até se tornar o expoente de uma das teorias da história com mais sucesso na atualidade. Não fica claro, porém, até que ponto se pode pensar em Koselleck como um outsider. Com o benefício da retrospectiva, podemos apreciar que ele não somente acabou por representar o mainstream da profissão histórica, mas também que ele começou a sua carreira sob a elite intelectual alemã e nunca deixou de pertencer a ela. Em primeiro lugar, Koselleck foi sempre identificado como o protegé de Carl Schmitt, que, embora jubilado da universidade devido ao seu envolvimento com o nacional-socialismo e a seu antissemitismo confesso e impenitente, continuou (e continua) exercendo uma forte influência na intelectualidade alemã. Mas não só isso; como é relatado pelo próprio Olsen, Koselleck ingressou na Universidade de Heidelberg sob os cuidados do prestigiado historiador Johannes Kühn, que era, aliás, o seu tio, e desenvolveu toda a primeira parte dos estudos que o posicionaram na primeira linha da profissão histórica no grupo de estudos de dois dos historiadores que assumiram a condução efetiva da profissão histórica alemã, W. Conze e O. Brunner. E tudo isso antes de que a validade dos seus trabalhos fosse questionada em relação à sua participação no regime hitleriano. Seja como for, tomando as descrições do livro de Olsen como referência, fica difícil explicar a origem ou o sentido da caracterização de Koselleck como outsider: Koselleck nasceu em uma família tradicional alemã, formou-se na universidade mais 
prestigiada da Alemanha do pós-guerra, cercado e apadrinhado pelos maiores intelectuais da sua área e ocupando-se dos assuntos que preocupavam à maioria dos seus colegas.

Para além desses problemas, o leitor sente a falta de alguma tentativa de esboço cronológico mais formal que permita localizar com maior exatidão os trabalhos discutidos na biografia dentro da trajetória intelectual geral de Koselleck para, assim, relacioná-los com aqueles que não foram levados em consideração pelo autor. Apesar de nomear em várias oportunidades a relação entre a sua pesquisa historiográfica e os desafios políticos contemporâneos, Olsen tampouco faz um esforço por encaixar o pensamento do historiador em eventos relevantes da história política, social ou intelectual na qual construiu a sua teoria da história. Ao estar organizado a partir da intepretação dos textos koselleckianos, muitas vezes fica difícil acompanhar, no livro resenhado, a passagem do historiador entre os diversos círculos intelectuais dos quais fez parte. Essa abertura matizaria a imagem de totalidade que por momentos se projeta sobre a obra do biografado, como se a sua trajetória fosse uma curva ascendente em direção ao desenvolvimento, por sua parte, da Historik. O resultado é uma série de interpretações geralmente laudatórias que, não obstante, não fazem justiça à obra do biografado e que tampouco contribuem para o aprofundamento da tão pouco visitada e interessantíssima discussão historiográfica que uma boa história intelectual poderia desvelar. Resta, assim, muito por fazer. A obra de Koselleck continua a aguardar o seu intérprete. 